\title{
Impact of the oxaliplatin-5 fluorouracil-folinic acid combination on respective intracellular determinants of drug activity
}

\author{
JL Fischel', P Formento', J Ciccolini' ${ }^{2}$ P Rostagno', MC Etienne', J Catalin ${ }^{2}$ and G Milano*,I \\ 'Centre Antoine Lacassagne, Oncopharmacology Unit, 33, Avenue de Valombrose, 06189 Nice Cedex 2, France; ${ }^{2}$ School of Pharmacy, Pharmacokinetics Unit, \\ Marseille, France
}

The combination of 5-fluorouracil-folinic acid and oxaliplatin has led to a significant improvement of chemotherapy efficacy in advanced pretreated colorectal cancer. The objective of the present study was, considering the oxaplatin-5-fluorouracil-folinic acid combination, to examine the impact of one given drug on the cellular determinants of cytotoxic activity of the other drug. These cellular factors were analysed on the human colon cancer cell line WiDr in clinically relevant conditions of drug exposure ('De Gramont' schedule) with oxaliplatin-folinic acid during $2 \mathrm{~h}$ followed by 5 -fluorouracil $48 \mathrm{~h}$. The DNA binding of oxaliplatin was significantly reduced by the presence of 5 -fluorouracil but this effect was time-dependent and after $50 \mathrm{~h}$ the platinum incorporated into DNA was identical in controls and in the drug combination. In the presence of oxaliplatin, there was less formation of $\mathrm{FUH}_{2}$ which is the first catabolite produced in the cascade of 5-fluorouracil metabolic degradation. The effects of drugs on cell cycle were quite different from one drug to the other with oxaliplatin inducing a shift towards $G_{2}$ accumulation and 5-fluorouracil-folinic acid to a greater proportion of cells in $\mathrm{G}_{1}-\mathrm{S}$. When oxaliplatin and 5-fluorouracil-folinic acid were combined the cell cycle effects were very similar to that of the 5 -fluorouracil-folinic acid sequence alone. Oxaliplatin was able to reduce thymidylate synthase activity with a marked impact $28 \mathrm{~h}$ after the beginning of cell exposure to the drug. The 5-fluorouracil-folinic acid drug sequence led to a profound reduction in thymidylate synthase activity and this decrease was not markedly enhanced by the presence of oxaliplatin. Regarding apoptosis, changes in mitochondrial membrane permeability were observed in the presence of the tested drugs and the impact of 5 -fluorouracil-folinic acid was greater than that of oxaliplatin. The addition of oxaliplatin did not amplify the action of 5-fluorouracil-folinic acid upon mitochondrial membrane permeability change. The presence of oxaliplatin itself did not modify the intracellular concentration of total reduced folates. The fact that oxaliplatin may reduce 5 -fluorouracil catabolism could be central in explaining the supra-additive interaction between these drugs.

British Journal of Cancer (2002) 86, II62- I |68. DOI: 10.1038/sj/bjc/6600 I85 www.bjcancer.com

(c) 2002 Cancer Research UK

Keywords: 5-fluorouracil; oxaliplatin; drug interactions; WiDr cell line

Colorectal cancer remains a leading cause of cancer deaths in western countries and approximately half of all patients develop metastatic disease carrying a poor prognosis. Chemotherapy still represents the treatment of choice for palliative purposes. The efficacy of chemotherapy in advanced colorectal cancer has significantly progressed during the last two decades. Folinic acid (FA) modulation of 5-fluorouracil (FU) has markedly increased the tumour response rate and, more recently, new drugs have emerged in the arena of colorectal cancer treatment. Irinotecan and oxaliplatin (Oxa) are representative of these new active drugs. Irinotecan (CPT 11) is a topoisomerase I inhibitor which prolongs patient survival as a second-line treatment in advanced colorectal cancer resistant to FU (Van Cutsem et al, 1999). Oxa displays activity not only in patients with platinum-sensitive malignancies such as ovarian tumours but also in those with colorectal cancer, a disease known for its resistance to both cisplatin and carboplatin (Judson and Kelland, 2000). Recently, combinations of FUFA and irinotecan or of FUFA and Oxa have led to a further improvement of chemotherapy efficacy in advance pretreated colorectal cancer

*Correspondence: G Milano; E-mail: gerard.milano@cal.nice.fr Received I9 July 200 I; revised 23 October 200 I; accepted I0 January 2002
(André et al, 1998; Ducreux et al, 1999). Importantly, a recent controled trial has established the superiority of Oxa-FUFA over FU FA in terms of response rate and progression-free survival (De Gramont et al, 2000). The high antitumour efficacy of this combination protocol is in agreement with preclinical data (Raymond et al, 1997) showing the synergistic cytotoxic activity of the Oxa-FUFA association.

The objective of the present study was, when considering the Oxa-FUFA combination, to examine the impact of one given drug on the cellular determinants of cytotoxic activity of the other drug. Different potentially relevant cellular parameters for the activity of combined drugs were analysed on the human colon cancer cell line WiDr in clinically relevant conditions of drug exposure. The tested drug sequence was Oxa-FA during $2 \mathrm{~h}$ followed by FU during $48 \mathrm{~h}$. This sequence faithfully matches the currently applied clinical protocol derived from the 'De Gramont' schedule (De Gramont et al, 2000). The choice of cellular parameters was dictated by the respective mechanisms of action of FU and Oxa. These parameters were: the incorporation of platinum $(\mathrm{Pt})$ in nucleic acids, the levels of thymidylate synthase (TS) activity and TS protein, the intracellular profile of FU metabolism, the incorporation of FU metabolites in nucleic acids, the intracellular levels of reduced folates and cell cycle analysis. In addition, the impact on apoptosis 
of individual drugs and drug combinations was taken into account. For this latter purpose, change in mitochondrial membrane permeability was examined as it is one of the key events initiating the apoptotic process.

\section{METHODS}

\section{Chemicals}

All the chemicals were obtained from Sigma Chemical Co (St Quentin Fallavier, France) and were of the highest purity available. Regular DMEM and glutamine were obtained from Whittaker (Verviers, Belgium) and foetal bovine serum from Dutscher (Brumath, France). Penicillin and streptomycin were obtained from Merieux (Lyon, France). FU and Oxa were the pharmaceutical forms obtained from Roche (Neuilly/Seine, France) and Sanofi Synthelabo (Gentilly, France), respectively. FA (racemic mixture) was from Sigma Chemical Co.

\section{Drug administration schedule}

The human colorectal cancer cell line, WiDr, was used in the present study. Cells were routinely cultured in DMEM supplemented with $10 \%$ foetal bovine serum, 2 mM glutamine, 50000 units $^{-1}$ penicillin and $80 \mu \mathrm{M}$ streptomycin in a humidified incubator (Sanyo, Japan) at $37^{\circ} \mathrm{C}$ with an atmosphere containing $8 \% \mathrm{CO}_{2}$. One week before commencement of the experiments, the cells were grown in a folate-controlled medium (folic acid-free DMEM supplemented with $40 \mathrm{nM}$ of DL-5 methyltetrahydrofolate and $0.1 \mathrm{mM}$ of L-ascorbate) to simulate as closely as possible the physiological conditions encountered in humans (Kones, 1990). The above folate-controlled medium was used throughout the experiments.

Cells were plated in 96-well microtitration plates $(100 \mu \mathrm{l}$ well $^{-1}$ ) to obtain exponential growth for the whole duration of the experiment (initial cell density was 2500 cells per well). Twenty-four hours later, cells were exposed to the drugs. Cytotoxic efficacy of drugs taken alone was first considered. This permitted the determination of individual $\mathrm{IC}_{50}$ values (MTT test, Carmichael et al, 1987). Oxa (at $\mathrm{IC}_{50}=19.5 \mu \mathrm{M}$ ) and $\mathrm{d}, 1 \mathrm{FA}$ $(10 \mu \mathrm{M})$ were applied for $2 \mathrm{~h}$ followed by FU during $48 \mathrm{~h}$ (at $\left.\mathrm{IC}_{50}=13.5 \mu \mathrm{M}\right)$.

The cytotoxic effects resulting from this drug combination were checked in previously described experimental conditions (Fischel et al, 1998 unshown experiments). For a drug combination, the calculation of the Chou and Talalay (1984) combination index indicates the resulting effect of the drug association. A combination index at 1.00 means simple additivity, below 1 means synergy and higher than 1 means antagonism. A mean combination index of 0.8 was found in our experiment confirming the existence of slight synergistic (supra-additive) cytotoxic activity (Fischel et al, 1998). Cellular parameters were analysed between 2 and $98 \mathrm{~h}$ after the onset of different drug applications. Treated and control cells were collected at different sampling times $(2,8,28,50,74,98 \mathrm{~h}$ after the onset of Oxa applications). All investigations were duplicated at a distance.

\section{Cell cycle analysis}

The cell cycle was analysed by FACS according to the Vindelov and Christensen (1990) method. The percentage of cells in different cell cycle phases was determined by Modfit software.

\section{Evaluation of mitochondrial membrane permeability}

Cells were treated with or without various concentrations of drugs as described above. At various intervals, cells were washed with PBS, trypsinised and then placed in DMEM medium.
The measuring of $\Delta \Psi \mathrm{m}$ was performed with a cationic lipophilic fluorochrome: 3,3' dihexyloxacarbocyanine iodide $\left(\mathrm{DiOC}_{6}(3)\right)$ purchased from Sigma. Cells were incubated at $37^{\circ} \mathrm{C}$ for $15 \mathrm{~min}$ in the presence of $\mathrm{DiCO}_{6}(3) 40 \mathrm{nM}$, then placed on ice followed by addition of propidium iodide $10 \mu \mathrm{g} \mathrm{ml}^{-1}$. The fluorochrome incorporations were immediately analysed using a Becton Dickinson FACScan flow cytometer at an excitation wavelength of $488 \mathrm{~nm}$. PI was used in all samples to exclude dead cells from the analysis. $\operatorname{DiOC}_{6}(3)$ fluorescence was recorded in FL1 and PI was recorded in FL3. The percentage of apoptosis cells was calculated from an FL1/FL3 scattergram. All experiments were repeated three times.

\section{TS measurements and reduced folate determination}

- TS activity was measured according to the tritium-release assay described by Spears and Gustavsson (1988). The assay consisted in incubating $25 \mu \mathrm{L}$ of cytosol with ${ }^{3} \mathrm{H}$-dUMP ( $1 \mu \mathrm{M}$ final concentration) and 5,10-methylenetetrahydrofolate $\mathrm{CH}_{2} \mathrm{FH}_{4}$, $(0.62 \mathrm{mM}$ final concentration) in a total volume of $55 \mu \mathrm{L}$. After 0 (for blank substraction), 10,20 , and $30 \mathrm{~min}$ of incubation at $37^{\circ} \mathrm{C}$, the reaction was stopped in ice. The excess of ${ }^{3} \mathrm{H}$-dUMP was removed by adding $300 \mu \mathrm{L}$ of activated charcoal (15\%) containing $4 \%$ trichloroacetic acid (5-min centrifugation at $14000 \mathrm{~g}$, room temperature). The ${ }^{3} \mathrm{H}_{2} \mathrm{O}$ formed during the incubation was then counted in an aliquot of the above supernatant. Results were expressed as fmoles of ${ }^{3} \mathrm{H}_{2} \mathrm{O}$ formed per min per $\mathrm{mg}$ of protein, based on the linear regression obtained from the incubation times. The sensitivity limit was $10 \mathrm{fmol}$ $\min ^{-1} \mathrm{mg}^{-1}$ prot. Inter-assay reproducibility was evaluated through repeated analysis of single-use aliquots of a pooled cytosol: $n=5$, mean $=1110 \mathrm{fmol} \mathrm{min}{ }^{-1} \mathrm{mg}^{-1}$ prot, s.d. $=78.59 \mathrm{fmol}$ $\min ^{-1} \mathrm{mg}^{-1}$ prot, $\mathrm{CV}=7.08 \%$.

- Concentration of total reduced folates $\left(\mathrm{CH}_{2} \mathrm{FH}_{4}+\mathrm{FH}_{4}\right)$ and total TS protein were measured with the radioenzymatic method previously described by Bunni et al (1988). The ternary stable complex ${ }^{3} \mathrm{HFdUMP}-\mathrm{TS}-\mathrm{CH}_{2} \mathrm{FH}_{4}$ was used as a trap for the measurement of either TS or total reduced folates:

- Measurement of TS protein with excess of ${ }^{3}$ HFdUMP and $\mathrm{CH}_{2} \mathrm{FH}_{4}$.

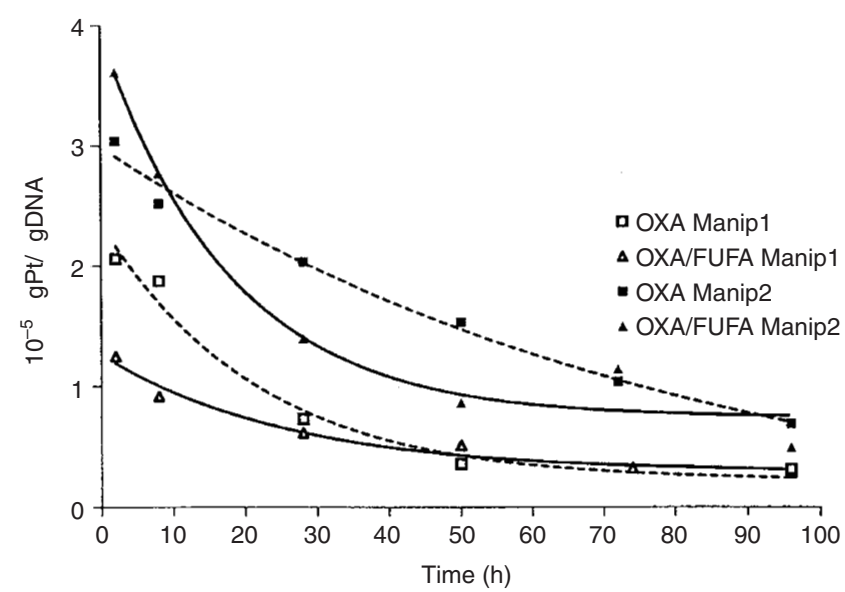

Figure I Time course of Pt concentration in DNA for the WiDr cell line (as \% of maximum incorporation: $2 \mathrm{~h}$ exposure Oxa alone (two independent experiments). Solid and open squares and dashed line: Oxa alone. Solid and open triangles and solid line: Oxa+FUFA. The Pt incorporations are statistically different between the two conditions Oxa vs Oxa+FUFA. $P=0.0055$ (paired $t$-test on all shown data). 
- Measurement of total reduced folates with excess of ${ }^{3} \mathrm{HFdUMP}$ and TS (presence of formaldehyde allowing the conversion of $\mathrm{FH}_{4}$ into $\mathrm{CH}_{2} \mathrm{FH}_{4}$ ).

- The excess of radioactivity was retained on Sephadex columns and the eluted fraction was counted by liquid scintillation. The sensitivity limit for TS was $0.010 \mathrm{pmol} \mathrm{mg}^{-1}$ prot with a $\mathrm{CV}=15 \%$. The sensitivity limit for total reduced folates was 0.3 pmoles $\mathrm{mg}^{-1}$ prot with a $\mathrm{CV}=10 \%$.

\section{Drug incorporations in nucleic acids}

Platinum incorporation into DNA was measured as follows: after isolation of DNA on Qiagen $(\mathbb{R})$ columns by ionic strength elution, DNA platinum incorporation was measured using Atomic Absorption Spectrophotometry.

${ }^{14} \mathrm{C}$ FU incorporation into RNA and DNA was determined as follows: WiDr cells growing exponentially in $25 \mathrm{~cm}^{2}$ flasks were put in contact at different exposure times $-8,28,50,74,96 \mathrm{~h}$ with ${ }^{3} \mathrm{H} \mathrm{FU}\left(13.5 \mu \mathrm{M}\right.$, specific activity $\left.56 \mathrm{mCi} \mathrm{mMole}^{-1}\right)$ with or without FA $(10 \mu \mathrm{M})$ and Oxa $(19.6 \mu \mathrm{M})$ DNA and RNA were isolated
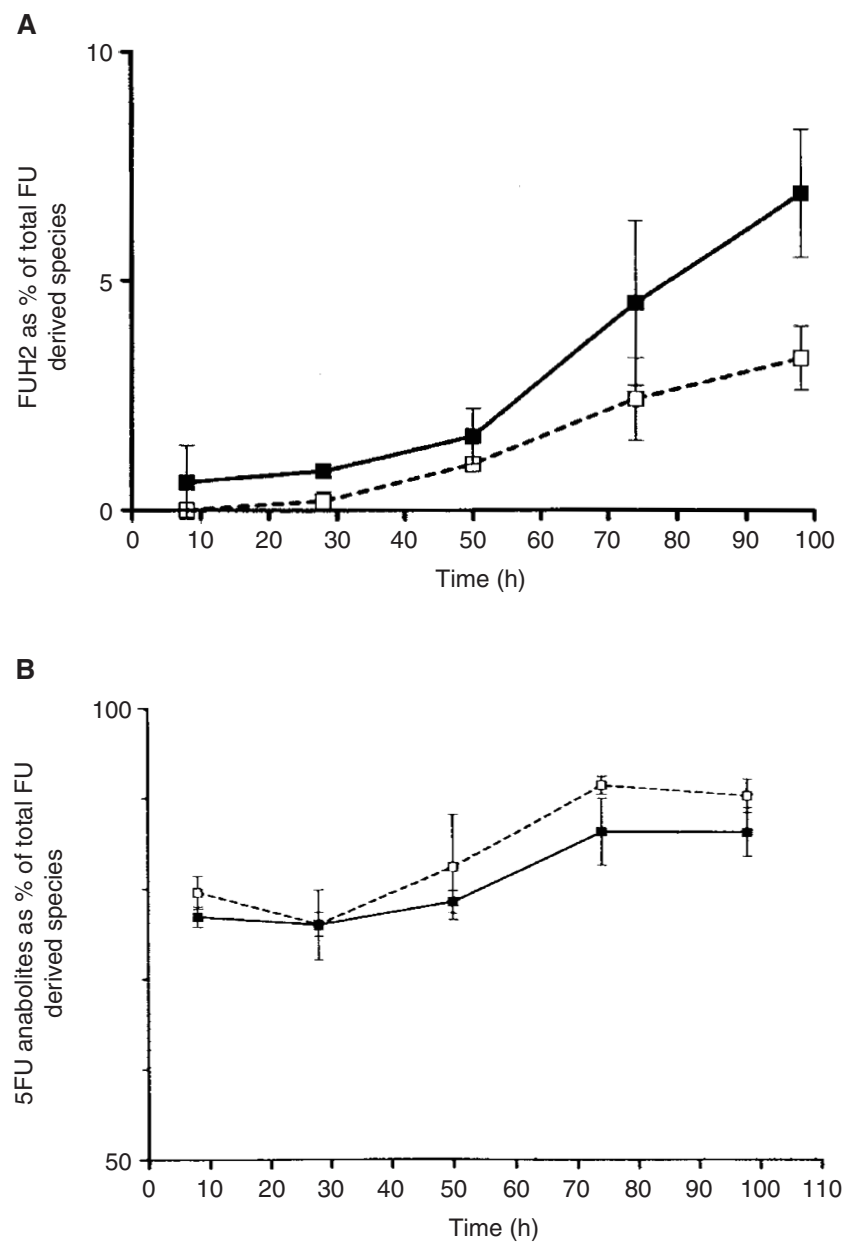

Figure 2 (A) Time course of FUH2 concentration (as \% of total FU derived chemical species). Solid square and solid line: FUFA alone. Open square and dashed line: FUFA+Oxa. Bars represent Standard Deviations (two independent experiments). The two curves are statistically different $P=0.0042$ (paired $t$-test). (B) Time course of anabolites concentration (sum of FUrd, FUMP, FUDP, FUTP, FdUrd, FdUMP, FdUDP, FdUTP). Solid square and solid line: FUFA alone. Open square and dashed line: FU FA+Oxa. Bars represent Standard Deviations (two independent experiments). The two curves are statistically different $P=0.0096$ (paired $t$-test) on Qiagen $\mathbb{R}$ columns. Radioactivity incorporation was evaluated on a liquid scintillation counter.

\section{Analysis of intracellular metabolism of 5-FU}

${ }^{3} \mathrm{H}$ FU metabolites were separated by HPLC and counted on line by radioactivity monitoring as described previously (Ciccolini et al, 2000). Exponentially growing cells were exposed to various combination of $100 \mu \mathrm{Ci}$ of tritiated $\mathrm{FU}$ (final concentration $2 \mu \mathrm{M})$. Cells were harvested and cytosols were isolated for HPLC analysis. The HPLC consisted of an HP 1090 (Hewlett Packard) system coupled with an A 200 radioactive flow detector (Packard). Separation of tritiated metabolites was achieved using a Lichrospher 100 RP $18 \quad 5 \mu \mathrm{M}$ column (Hewlett Packard) eluted by $50 \mathrm{mM} \mathrm{K}_{2} \mathrm{HPO}_{4}$ (pH 6.8) containing $1 \mathrm{mM}$ tetrabutyl ammonium nitrate and $12 \%(0-9 \mathrm{~min})$ to $16 \%(9-60 \mathrm{~min})$ methanol.

\section{Statistical analysis}

Comparisons between different tested conditions were done with Wilcoxon non parametric paired tests for experiments described in Figures 1, 2A,B and 3. Comparisons between different tested conditions were done with Mann-Whitney unpaired non parametric test for experiments described in Figures 5A,B and 6.

\section{RESULTS}

Figure 1 depicts the impact of the presence of $\mathrm{FU}$ on the incorporation of Pt into DNA. Although not superimposable due to experiments performed at distance, the results shown in Figure 1 point out that DNA binding of Oxa was significantly reduced by the presence of $\mathrm{FU}$ but this effect was time-dependent and after $50 \mathrm{~h}$ the $\mathrm{Pt}$ incorporated into DNA was identical in controls (Oxa alone) and in the drug combination (Oxa FUFA sequence).

The presence of Oxa was found to modify the intracellular metabolic profile of FU. Under Oxa, there was less formation of $\mathrm{FUH}_{2}$ (Figure 2A), which is the first catabolite produced in the cascade of FU metabolic degradation. Conversely, more FU anabolites were formed in the presence of Oxa (Figure 2B). When

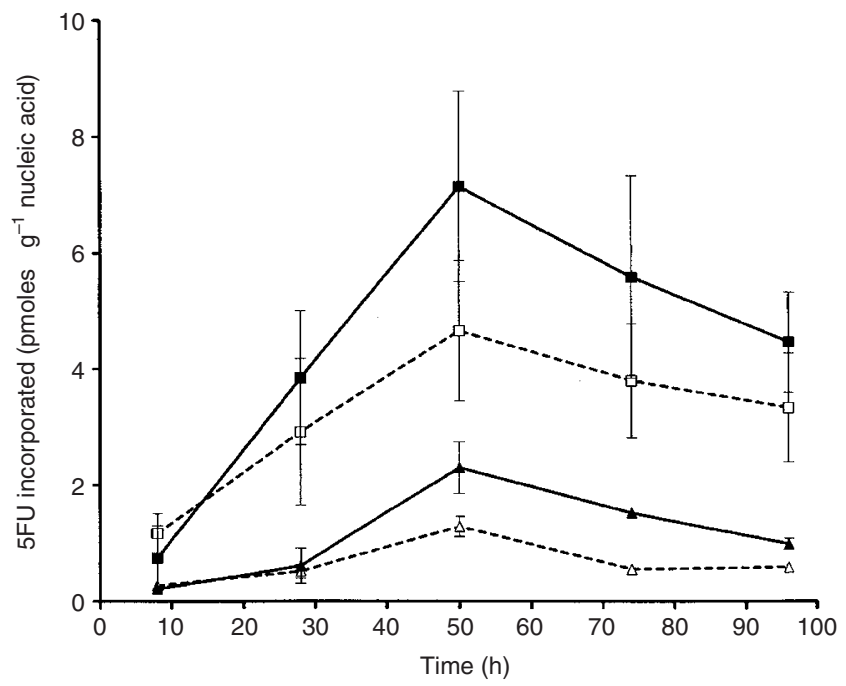

Figure 3 Time course incorporation of ${ }^{14} \mathrm{CFU}$ in nucleic acids. Solid square and solid line: DNA, FUFA alone. Open square and dashed line: DNA, FUFA+Oxa. Solid triangle and solid line: RNA, FUFA alone. Open triangle and dashed line: RNA, FUFA+Oxa. Bars represent Standard Deviations (two independent experiments). The two curves of RNA incorporation are statistically different $P=0.0066$. The two curves of DNA incorporation are statistically different $P=0.0 .156$ (paired $t$-test). 
considering the global incorporation of ${ }^{14} \mathrm{CFU}$ into nucleic acids, and contrary to expectations, there were fewer FU-related compounds present in nucleic acids following the Oxa FUFA sequence as compared to FUFA alone (Figure 3).

The respective impacts of Oxa and Oxa_FUFA on cell cycle organisation are detailed in Table 1 . These effects on cell cycle are quite different from one drug to the other with Oxa inducing a shift towards $G_{2}$ accumulation and FUFA leading to a greater proportion of cell in $G_{1}-S$ and a lower proportion in $G_{2}$ phase. It is interesting to note that when Oxa and FUFA were combined the cell cycle effects were very similar to that of the FUFA sequence alone (Table 1).

The modifications in TS activity and TS protein levels under drug applications are shown in Figure $4 \mathrm{~A}$ and $\mathrm{B}$ respectively. This

Table I Time course of the impact of drugs on cell cycle

\begin{tabular}{|c|c|c|c|c|c|c|}
\hline \multirow{2}{*}{\multicolumn{2}{|c|}{ Experimental conditions }} & \multirow[b]{2}{*}{ Time (h) } & \multicolumn{3}{|c|}{ Cell cycle (\% cells) } & \multirow{2}{*}{$\begin{array}{c}\text { Apoptosis (mitochondrial } \\
\text { permeability) }\end{array}$} \\
\hline & & & GI & $\mathbf{S}$ & G2 & \\
\hline & & 2 & & & & \\
\hline \multirow{2}{*}{ Control } & mean & & 56.54 & 33.60 & 9.86 & ND \\
\hline & s.d. & & 6.13 & 4.99 & 1.22 & ND \\
\hline \multirow[t]{2}{*}{ OXA } & mean & & 52.55 & 36.76 & 10.68 & ND \\
\hline & s.d. & & 5.17 & 2.59 & 2.99 & ND \\
\hline \multirow{2}{*}{ FUFA } & mean & & 53.61 & 36.03 & 10.35 & ND \\
\hline & s.d. & & 3.76 & 1.33 & 2.74 & ND \\
\hline \multirow[t]{3}{*}{ OXA FUFA } & mean & & 53.92 & 37.22 & 8.86 & ND \\
\hline & s.d. & & 3.08 & 1.65 & 2.12 & ND \\
\hline & & 8 & & & & \\
\hline \multirow[t]{2}{*}{ Control } & mean & & 52.87 & 35.67 & 11.46 & 3.85 \\
\hline & s.d. & & 0.16 & 0.29 & 0.19 & 0.79 \\
\hline \multirow[t]{2}{*}{ OXA } & mean & & 51.50 & 41.63 & 6.87 & 3.70 \\
\hline & s.d. & & 2.71 & 3.52 & 1.54 & 0.78 \\
\hline \multirow[t]{2}{*}{ FUFA } & mean & & 52.89 & 42.25 & 4.86 & 3.75 \\
\hline & s.d. & & 1.83 & 1.48 & 0.52 & 1.03 \\
\hline \multirow[t]{3}{*}{ OXA FUFA } & mean & & 52.29 & 42.00 & 5.71 & 3.18 \\
\hline & s.d. & & 0.49 & 0.60 & 0.15 & 0.95 \\
\hline & & 28 & & & & \\
\hline \multirow[t]{2}{*}{ Control } & mean & & 55.67 & 34.68 & 9.65 & 4.03 \\
\hline & s.d. & & 4.35 & 5.61 & 1.30 & 0.55 \\
\hline \multirow[t]{2}{*}{ OXA } & mean & & 40.22 & 23.27 & 36.51 & 5.80 \\
\hline & s.d. & & 1.35 & 4.04 & 2.69 & 1.07 \\
\hline \multirow[t]{2}{*}{ FUFA } & mean & & 51.65 & 47.79 & 0.59 & 5.28 \\
\hline & s.d. & & 7.78 & 7.18 & 0.65 & 0.71 \\
\hline \multirow[t]{3}{*}{ OXA FUFA } & mean & & 55.27 & 42.79 & 1.94 & 6.04 \\
\hline & s.d. & & 2.73 & 4.14 & 1.48 & 1.34 \\
\hline & & 50 & & & & \\
\hline \multirow[t]{2}{*}{ Control } & mean & & 60.88 & 27.04 & 12.08 & 4.11 \\
\hline & s.d. & & 3.77 & 4.32 & 0.68 & 0.88 \\
\hline \multirow[t]{2}{*}{ OXA } & mean & & 35.42 & 20.11 & 44.47 & 8.19 \\
\hline & s.d. & & 7.84 & 7.82 & 0.93 & 3.26 \\
\hline FUFA & mean & & 61.86 & 38.08 & 0.07 & 11.26 \\
\hline & s.d. & & 2.30 & 2.24 & 0.05 & 2.71 \\
\hline OXA FUFA & mean & & 59.55 & 40.32 & 0.12 & 10.86 \\
\hline & s.d. & & 5.57 & 5.65 & 0.13 & 5.71 \\
\hline & & 74 & & & & \\
\hline Control & mean & & 66.29 & 22.76 & 10.82 & 4.82 \\
\hline & s.d. & & 6.23 & 3.16 & 3.71 & 1.36 \\
\hline OXA & mean & & 23.44 & 48.29 & 28.28 & 10.00 \\
\hline & s.d & & 3.14 & 14.75 & 11.87 & 2.75 \\
\hline FUFA & mean & & 4.87 & 87.46 & 7.67 & 31.06 \\
\hline & s.d. & & 1.06 & 6.10 & 5.54 & 12.09 \\
\hline OXA FUFA & mean & & 3.34 & 91.75 & 4.91 & 30.33 \\
\hline & s.d. & & 0.86 & 5.00 & 4.70 & 10.83 \\
\hline & & 98 & & & & \\
\hline Control & mean & & 56.73 & 30.36 & $|2.9|$ & 6.05 \\
\hline & s.d. & & 15.50 & 9.98 & 5.52 & 0.61 \\
\hline OXA & mean & & 38.16 & 32.19 & 29.65 & 9.81 \\
\hline & s.d. & & 8.36 & 4.02 & 5.93 & 1.60 \\
\hline FUFA & mean & & 5.81 & 86.49 & 7.70 & 34.26 \\
\hline & s.d. & & 4.86 & 7.63 & 4.88 & 11.20 \\
\hline OXA FUFA & mean & & 4.98 & 87.81 & 7.21 & 30.54 \\
\hline & s.d. & & 4.65 & 8.96 & 4.45 & 8.46 \\
\hline
\end{tabular}

For cell cycle analysis and evaluation of mitochondrial membrane permeability, refer to Materials and Methods. Unit for the quantification of mitochondrial membrane permeability is the percentage of stained cells. Experiments were repeated three times at distance. 
A

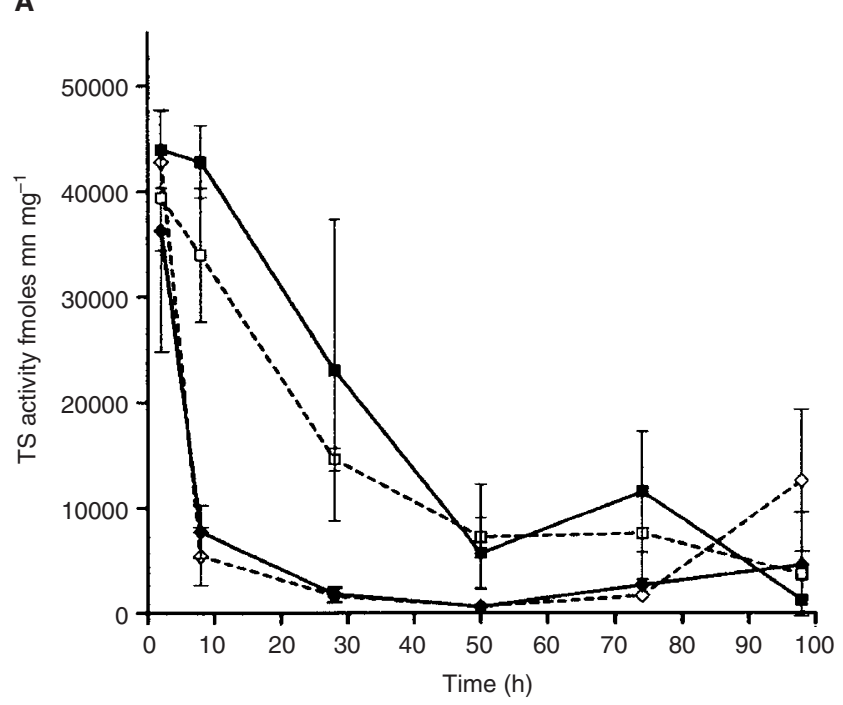

B

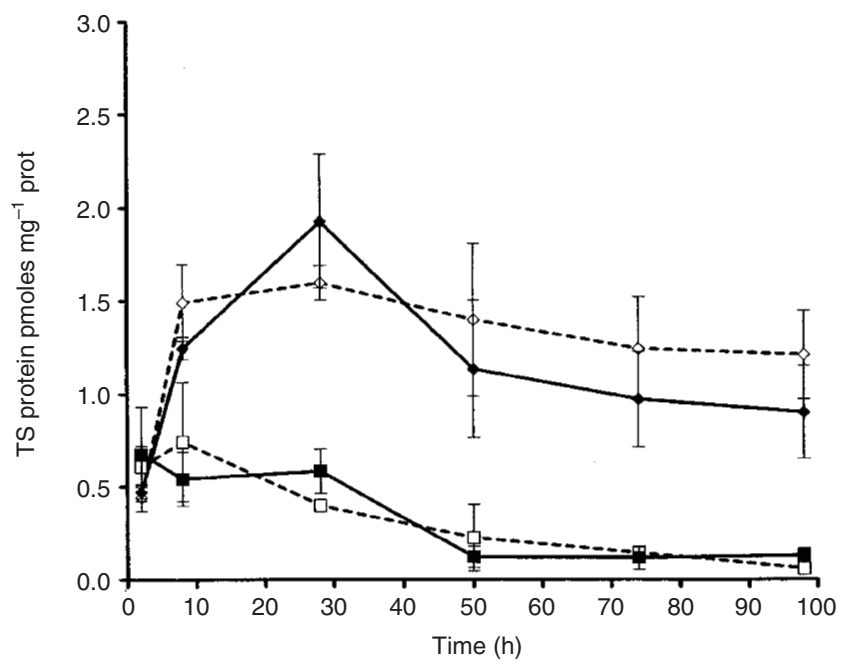

Figure 4 (A) Time course of TS activity. Solid square and solid line: Control without drugs. Open square and dashed line: Oxa alone. Solid diamond and solid line: FUFA alone. Open diamond and dashed line: FUFA+Oxa. Bars represent Standard Deviations (two independent experiments). The curves Control and Oxa alone do not differ significantly. FUFA alone and FUFA+Oxa do not differ significantly. Control and FUFA alone differ significantly $P=0.0163$. Oxa alone and FUFA+Oxa differ significantly $P=0.0034$. Non parametric unpaired test. (B) Time course of TS protein. Solid square and solid line: Control without drugs. Open square and dashed line: Oxa alone. Solid diamond and solid line: FUFA alone. Open diamond and dashed line: FUFA+Oxa. Bars represent Standard Deviations (two independent experiments). The two curves control and Oxa alone do not differ significantly. FUFA alone and FUFA+Oxa do not differ significantly. Control and FUFA alone differ significantly $P<0.01$. Oxa alone and FUFA+Oxa differ significantly $P<0.001$.

reduction in TS activity of the control cells may be attributable to progressive cellular confluence in the small well plates. It appears that Oxa alone is able to reduce TS activity with a marked impact $28 \mathrm{~h}$ after the beginning of cell exposure to the drug. The FUFA drug sequence leads to a profound reduction in TS activity. Although this decrease is enhanced in its early phase $(8 \mathrm{~h})$ by the presence of Oxa (Figure 4A) the 'FUFA alone' curve and the 'FUFA+OXA' curve are almost identical. An early, marked and sustained rebound in TS protein is observed after cell exposure

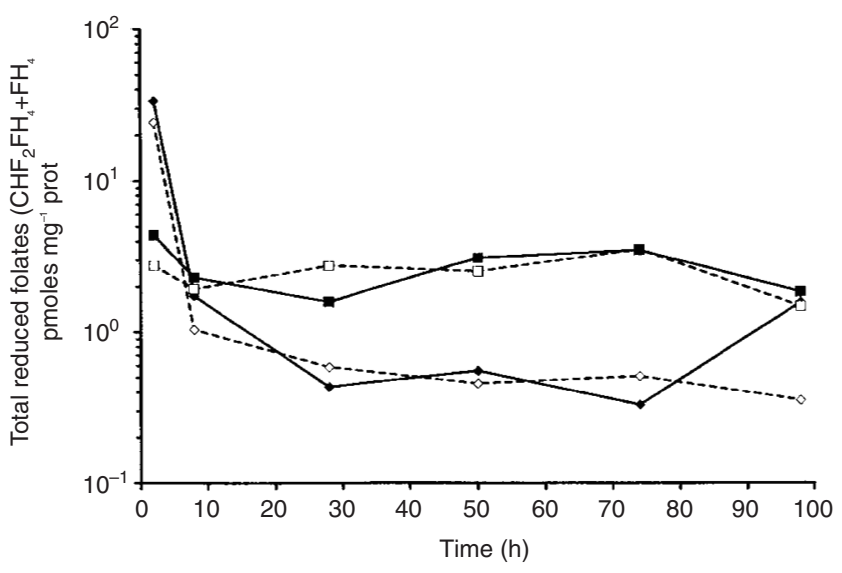

Figure 5 Time course of total reduced folates concentration (logarithmic scale, s.d. varied between 0.009 and 1.94). Solid square and solid line: control without drugs. Open square and dashed line: Oxa alone. Solid diamond and solid line: FUFA alone. Open diamond and dashed line: FUFA+Oxa. The two curves: control and Oxa alone are not statistically different. FUFA alone and FUFA+Oxa are not statistically different. Control and FUFA alone are statistically different $P=0.0469$. Oxa alone and FU$F A+O x a$ are statistically different $P=0.039$

to FUFA. This rebound was found to be maintained in the presence of Oxa (Figure 4B).

Changes in mitochondrial membrane permeability were observed in the presence of the tested drugs. These effects are detailed in Table 1. The impact of FUFA is greater than that of Oxa. The maximal effect of Oxa is observed at $74 \mathrm{~h}$ whereas FUFA has maximal impact at $98 \mathrm{~h}$. Globally, the addition of Oxa does not amplify the action of FUFA upon mitochondrial membrane permeability change.

The intracellular evolution of total reduced folates is shown in Figure 5. The initial decrease in total reduced folates is due to the changing of the medium from $10 \mu \mathrm{M}$ FA during the first $2 \mathrm{~h}$ of drug exposure to normal medium conditions. The presence of Oxa itself does not modify the intracellular concentration of reduced folates. Noteworthy, it was found that a marked decrease in reduced folate levels occurred in the presence of FUFA. This time profile of intracellular reduced folates was very similar to that observed when adding Oxa to FUFA (Figure 5).

\section{DISCUSSION}

The objective of the present study was, when considering the OxaFUFA combination, to examine the impact of one given drug on the cellular determinants of cytotoxic activity of the other drug. To that end, the individual cellular targets of the considered drugs were examined. The clinically relevant drug sequence consisting in Oxa-FA, $2 \mathrm{~h}$ followed by FU, $48 \mathrm{~h}$ (De Gramont et al, 2000), was adopted in the present study. The supra-additive interaction which had previously been shown (Fischel et al, 1998) was confirmed in the present study on the WiDr human colon cancer cell line using the same conditions (drugs, concentration, time of exposure) used for the previously published results. The presence of cytotoxic synergy between Oxa and FU had been previously reported by Raymond et al (1997) with both in vitro and in vivo data on human HT 29 colon cancer xenografts. In this latter study, examining possible explanatory factors, the authors failed to show that FU could significantly modify the tumoural total Pt DNA binding of Oxa during Oxa-FUFA combination treatment. In the present study, it was shown that the addition of FU to OXA resulted in a decrease of Pt binding to DNA (Figure 1). However, this reduction of Pt binding is moderate and one of the possible reasons for 
this phenomenon, which occurs during cell exposure to $\mathrm{FU}$, may lie in the fact that FU anabolites can be fraudulously incorporated into RNA and DNA (Grem, 2000) and this incorporation may compromise the binding of $\mathrm{Pt}$ to nucleic acids. Conversely, and probably for the same reasons of reciprocal impairment of nucleic acid drug binding, it was found that, during cell exposure to OxaFUFA, there were fewer FU anabolites incorporated into nucleic acids as compared to what is observed with the FUFA sequence alone (Figure 3 ).

In the present study, using flow cytometry analysis, it was shown that the FUFA sequence induces an accumulation of cells in the $G_{1}$ early $S$ phase. This observation is in agreement with known comparable data (Pizzorno et al, 1995) recently confirmed by Backus et al (2001). The impact of Oxa on cell cycle with an increased proportion of cells in the $G_{2}$ phase also concurs with the cell cycle effects of platinum derivatives (Mastbergen et al, 2000). Interestingly, after Oxa and FUFA combination, the organisation of cells within the cellular cycle $\left(G_{1}-S\right.$ shift $)$ was superimposable to that observed following FUFA alone (Table 1). This accumulation of cells in S phase is compatible with a slowdown of cell proliferation in agreement with the decrease in TS activity which was observed in the present study. Indeed, cell proliferation and TS activity are closely related as recently underlined by the data of Grem et al (2001).

The enzyme dihydropyrimidine dehydrogenase (DPD) regulates the FU catabolic route in liver and, importantly, at the tumoural cell level (Beck et al, 1994). The impact of the variability in tumoural DPD activity on FU cytotoxic activity has been previously demonstrated with both in vitro (Fischel et al, 1995) and in vivo data (Etienne et al, 1995). This resulted in the recent development of DPD inhibitors aimed at optimising FU-based chemotherapy (Hoff and Pazdur, 1999; Diasio, 2000). DPD activity was previously thought to be inhibited by cisplatin, a clinicallyproven FU modulator (Leteurtre et al, 1990; Nishiyama et al, 1999). Recent pharmacokinetic studies have suggested that Oxa may inhibit FU catabolism (Papamichael et al, 1998), although this finding was not confirmed by other investigators (Graham et al, 2000). The present investigation included a close examination of the main FU metabolic routes. At this level, it appears that in the presence of Oxa there was a significant decrease in the intracellular levels of $\mathrm{FUH}_{2}$. This points to the possibility that Oxa may inhibit DPD activity. Although a direct impact on DPD activity by Oxa was not tested in the present study, this potential DPD inhibition may be of prime importance for tumours which overexpress DPD since it has been shown that DPD-related resistance may be circumvented by the use of DPD inhibitors (Fischel et al, 1995). In this view, it is interesting to emphasise that new clinical responses have been observed when adding Oxa to FUFA in colorectal cancer patients resistant to FUFA (André et al, 1998; Garufi et al, 2000). The shift towards fewer catabolites and more anabolites of FU in the presence of Oxa was not however translated in the present study by an increase in FU anabolite incorporation into nucleic acids (Figure 3). The relative excess of the FU anabolite pool in the presence of Oxa may be at the origin of the more pronounced TS inhibition in the presence of Oxa FUFA (Figure $5 \mathrm{~A})$ but globally the impact of FUFA or OxaFUFA on TS activity was superimposable. Interestingly, it was also demonstrated that Oxa itself is able to inhibit TS activity (Figure 5A) but this effect

\section{REFERENCES}

André T, Louvet C, Raymond E, Tournigand C, De Gramont A (1998) Bimonthly high-dose leucovorin, 5 fluorouracil infusion and oxaliplation (FOLFOX 3) for metastatic colorectal cancer resistant to the same leucovorin and 5-fluorouracil regimen. Ann Oncol 9: 1251-1253 occurs later than the initial marked depletion in TS activity already induced by FUFA. This direct impact of Oxa on TS activity should be kept in mind and further explored in preclinical investigations or clinical studies with different Oxa-FUFA schedules. Other authors have pointed out an effect of Oxa on TS with a smaller FU-induced TSmRNA increase when Oxa is added to Fu (Plasencia et al, 2001). In contrast, the present data did not show that the presence of Oxa modified the FU-induced TS protein increase which had been previously described by Chu et al (1993).

Optimal inhibition of TS by FU required the formation of a ternary complex between TS, fluorodeoxyuridine monophosphate (a key anabolite of $\mathrm{FU}$ ) and a reduced folate, $\mathrm{CH}_{2} \mathrm{HF}_{4}$ (Keyomarsi and Moran, 1988). Experimental studies have established that the stabilisation of the ternary complex is enhanced by the presence of high levels of $\mathrm{CH}_{2} \mathrm{FH}_{4}$ (Moran and Scanlon, 1991). On this basis, clinical data have been provided that show better antitumour efficacy when $\mathrm{FU}$ is combined with leucovorin (folinic acid), a precursor of $\mathrm{CH}_{2} \mathrm{FH}_{4}$ (Etienne et al, 1996). We reported, in cancer patients treated by FU-based chemotherapy, that, at pretreatment stage, the tumoural concentration of reduced folates was a predictor of an objective response to treatment (Etienne et al, 1995). Cisplatin has been previously shown to upregulate the intracellular concentration of reduced folates (Vitols et al, 1987). We thus examined the possible impact of Oxa on the intracellular levels of total reduced folates. It was found that, in comparison to FUFA, the Oxa-FUFA sequence did not significantly modify the fate of the intracellular profile of reduced folates. The present study included an examination of drug-induced apoptotic events by considering the key step of apoptosis at the mitochondrial level. Both Oxa and FUFA were able to alter mitochondrial permeability with time-modulated effects (Table 1). It must be underlined that FUFA was more active than Oxa and that the addition of Oxa to FUFA did not change the impact on mitochondrial permeability already generated by FUFA. Other apoptotic pathways, like FAS-induced apoptosis, should be studied more closely as this pathway has been recently shown to play a major role in FU-mediated toxicity (Petak et al, 2000).

The present study examined the effects on respective cellular determinants of drug activity when combining Oxa and FUFA. The investigations covered the impact on drug targets, drug metabolism, cell cycle effect and apoptosis. Among the various factors explored, many failed to provide objective mechanistic explanations for the synergistic interaction between Oxa and FUFA in particular nucleic acid binding of respective drugs and intracellular concentration in reduced folates. In our opinion, the fact that Oxa may reduce FU catabolism at the DPD level could be central in explaining the supra-additive interaction between Oxa and FUFA. According to this hypothesis a DPD inhibitor could reduce the synergy of the Oxa FUFA combination. This must be kept in mind for further combinations between Oxa and recently-developed FU oral prodrugs containing a DPD inhibitor. It is possible that other molecular mechanisms may contribute to the supra-additive cytotoxic effects of the Oxa-FUFA combination. The present data may provide useful rational grounds for discussion when testing clinical confirmation of the impact of Oxa on FU catabolism. In this framework, exploring lymphocytic and tumoural DPD activity under Oxa treatment seems relevant.

Backus HH, Pinedo HM, Wouters D, Kuiper CM, Jansen G, van Groeningen CJ, Peters GJ (2001) Differences in the induction of DNA damage, cell cycle arrest, and cell death by 5-fluorouracil and antifolates. Oncol Res 12: $231-239$ 
Beck A, Etienne MC, Cheradame S, Fischel JL, Formento P, Renée N, Milano G (1994) A role for dihydropyrimidine dehydrogenase and thymidylate synthase in tumour sensitivity to fluorouracil. Eur J Cancer 30: 15171522

Bunni M, Doig MT, Donato H, Kesavan U, Priest DG (1988) Role of methylenetetrahydrofolate depletion in methotrexate-mediated intracellular thymidylate synthesis inhibition in cultured L1210 cells. Cancer Res 48: $3398-3404$

Carmichael J, De Graff W, Gazdar AF, Mumma JO, Mitchell JB (1987) Evaluation of tetrazolium-based semiautomated colorimetric assay: assessment of chemosensibility testing. Cancer Res 47: 936-940

Chu E, Koeller DM, Johnston PG, Zinn S, Allegra CJ (1993) Regulation of thymidylate synthase in human colon cancer cells treated with 5-fluorouracil and interferon-gamma. Mol Pharmacol 43: 527-533

Chou T, Talalay P (1984) Quantitative analysis of dose-effects relationships: the combined effects of multiple drugs or enzyme inhibitors. Adv Enzym Regul 22: $27-55$

Ciccolini J, Peillard L, Evrard A, Cuq P, Aubert C, Pelegrin A, Formento P, Milano G, Catalin J (2000) Enhanced antitumour activity of 5-fluorouracil in combination with $2^{\prime}$-deoxyinosine in human colorectal cell lines and human colon cancer xenografts. Clin Cancer Res 6: 1529-1535

De Gramont A, Figer A, Seymour M, Homerin M, Hmissi A, Cassidy J, Boni C, Cortes-Funes H, Cervantes A, Freyer G, Papamichael O, Le Bail N, Louvet C, Hendler O, De Braud F, Wilson C, Moran F, Bonetti A (2000) Leucovorin and fluorouracil with or without oxaliplation as firstline treatment in advanced colorectal cancer. J Clin Oncol 18: 2938-2947

Diasio R (2000) Oral DPD-inhibitory fluoropyrimidine drugs. Oncol 14: $19-$ 23

Ducreux M, Ychou M, Seitz JF, Bonnay M, Bexon A, Armand JP, Mahjoubi M, Mery-Mignard D, Rougier P (1999) Irinotecan combined with bolus fluorouracil, continuous infusion fluorouracil, and high dose leucovorin every two weeks (LV 5FU 2 regimen): a clinical dose-finding and pharmacokinetic study in patient with pre-treated metastatic colorectal cancer. $J$ Clin Oncol 17: $2901-2908$

Etienne MC, Cheradame S, Fischel JL, Formento P, Dassonville O, Renée N, Schneider M, Thyss A, Demard F, Milano G (1995) Response to fluorouracil therapy in cancer patients: the role of tumoural dihydropyrimidine dehydrogenase activity. J Clin Oncol 13: $1663-1670$

Etienne MC, Guillot T, Milano G (1996) Critical factors for optimizing for 5fluorouracil-folinic acid association in cancer chemotherapy. Ann Oncol 7: $283-289$

Fischel JL, Etienne MC, Spector T, Formento P, Renée N, Milano G (1995) Dihydropyrimidine dehydrogenase: a tumoural target for fluorouracil modulation. Experimental data. Clin Cancer Res 1: 991-996

Fischel JL, Etienne MC, Formento P, Milano G (1998) Search for the optimal schedule for the oxaliplatin/ 5 fluorouracil association modulated or not by folinic acid: preclinical data. Clin Cancer Res 4: 2529-2535

Garufi C, Brienza S, Pugliese P, Aschelter AM, Bensmaine, Bertheault-Cvitkovic F, Nistico C, Giunta S, Caterino M, Giannarelli D, Cosimelli M, Levi F, Terzoli E (2000) Overcoming resistance to chronomodulated 5-fluorouracil and folinic acid by the addition of chronomodulated oxaliplation in advanced colorectal cancer patients. Anti-Cancer Drugs 11: 495-501

Graham MA, Lockwood GF, Greenslade D, Brienza S, Bayssas M, Gamelin E (2000) Clinical pharmacokinetics of oxaliplatin: a critical review. Clin Cancer Res 6: 1205-1218

Grem J (2000) 5 fluorouracil: forty-plus and still ticking. A review of its preclinical and clinical development. Invest New Drugs 18: 299-313
Grem J, Danenberg K, Behan K, Parr A, Young L, Danenberg P, Nguyen D, Drake J, Monks A, Allegra C (2001) Thymidine kinase, thymidilate synthase, and dihydropyrimidine dehydrogenase profiles of cell lines of the National Cancer Institute's Anticancer Drug Screen. Clin Cancer Res 7: $999-1009$

Hoff PM, Pazdur R (1999) Dihydropyrimidine dehydrogenase inhibitory fluoropyrimidines: a novel class of oral antineoplastic agents. Sem Oncol 26: $52-56$

Judson I, Kelland LR (2000) New developments and approaches in the platinum arena. Drugs 59(Suppl 4): 29-36

Keyomarsi K, Moran RG (1988) Mechanism of the cytotoxic synergism of fluorouropyrimidines and folinic acid in mouse leukemic cells. J Biol Chem 28: $14402-14409$

Kones R (1990) Folic acid. An update with new recommended daily allowances. South Med J 83: 1454-1458

Leteurtre F, Croisy A, Perrin F, Carrez Z, Bastian G (1990) Pharmacokinetics of 5-fluorouracil in combination with cisplatin: evidence for drug interaction. Eur J Cancer 26S(200): (abstract 1223)

Mastbergen SC, Duivenvoorden I, Versteegh RT, Geldof AA (2000) Cell cycle arrest and clonogenic tumor cell kill by divergent chemotherapeutic drugs. Anticancer Res 20: $1833-1838$

Moran RG, Scanlon KL (1991) Schedule-dependent enhancement of the cytotoxicity of fluoropyridimes to human carcinoma cells in the presence of folinic acid. Cancer Res 51: 4618-4623

Nishiyama M, Yamamoto W, Park JS, Okamoto R, Hanaoka H, Takano H, Saito N, Matsukawa M, Shirasaka T, Kurihara M (1999) Low-dose cisplatin and 5-fluorouracil in combination can repress increased gene expression of cellular resistance determinants to themselves. Clin Cancer Res 5: $2620-2628$

Papamichael D, Joel S, Seymour M, Richards F, Bowerbank M, Slevin ML (1998) Pharmacokinetics interaction between 5-fluorouracil and oxaliplatin. Proc Am Soc Clin Oncol 17: 202

Petak I, Tillman DM, Houghton JA (2000) P53 dependence of FAS induction and acute apoptosis in response to 5-fluorouracil-leucovorin in human colon carcinoma cell lines. Clin Cancer Res 6: 4432 - 4441

Pizzorno G, Sun Z, Handschumacher RE (1995) Aberrant cell cycle inhibition pattern in human colon carcinoma cell lines after exposure to 5-fluorouracil. Biochem Pharmacol 49: 553-557

Plasencia C, Taron M, Martinez W, Rosell R, Abad A (2001) Down regulation of Thymidilate Synthase gene expression after Oxaliplation administration: Implications for the synergistic activity of the sequential Oxaliplatin/5FU in sensitive and 5FU resistant cell lines. Proc of AACR (abstract 2735)

Raymond E, Buquet-Fagot C, Djelloul S, Mester J, Cvitkovic E, Allain P, Louvet C, Gespach C (1997) Antitumor activity of oxaliplatin in combination with 5-fluorouracil and the thymidylate synthase inhibitor AG 337 in human colon, breast and ovarian cancers. Anti-Cancer Drugs 8: 876-885

Spears CP, Gustavsson BG (1988) Methods for thymidylate synthase pharmacokinetics: serial biopsy, free and total TS, FdUMP and dUMP, and H4 pte Glu and CH2-H4 Pte Glu assays. Adv Exp Med Biol 244: 97-106

Van Cutsem E, Peeters M, Verslype C, Filez L, Haustermans K, Janssens J (1999) The medical treatment of colorectal cancer: actual status and new developments. Hepatogastroenterology 46: 709-716

Vindelov L, Christensen JJ (1990) An integrated set of methods for routine flow cytometry DNA analysis. Methods Cell Biol 33: 127-137

Vitols KS, Montajeno Y, Duffy T, Pope L, Grundler G, Huennekens FM (1987) Platinum-folate compounds: synthesis, properties and biological activity. Adv Enzyme Regul 26: 17-27 